\title{
Self-reported prevalence of pulmonary symptoms in subjects with spinal cord injury
}

\author{
AM Spungen ${ }^{1,4,5}$, DR Grimm ${ }^{1,4}$, M Lesser $^{3,4}$, WA Bauman ${ }^{1,2,4,5}$ and PL Almenoff ${ }^{1,3,4}$ \\ ${ }^{1}$ Spinal Cord Damage Research Center, ${ }^{2}$ Spinal Cord Injury Service, ${ }^{3}$ Pulmonary/Critical Care Medicine, Veterans \\ Affairs Medical Center, Bronx, NY and the Departments of ${ }^{4}$ Medicine and ${ }^{5}$ Rehabilitation Medicine, Mount Sinai \\ School of Medicine, New York, NY, USA
}

To determine the prevalence of respiratory symptoms in subjects with chronic spinal cord injury (SCI), 180 subjects completed a standard respiratory questionnaire modified for subjects with limited mobility. Subjects were categorized as high tetraplegia (HT:C5 and above not requiring mechanical ventilation), low tetraplegia (LT: C6-8), high paraplegia (HP: T1 -7), or low paraplegia (LP: T8-L3). Overall, $68 \%$ of subjects reported one or more respiratory symptom. Breathlessness, the most prevalent complaint, was associated with level of lesion: $\mathrm{HT}=73 \%, \mathrm{LT}=58 \%, \mathrm{HP}=43 \%$ and $\mathrm{LP}=29 \%$, whereas complaints of cough, phlegm, cough and phlegm, and wheeze did not differ significantly among subjects in the four groups. Breathlessness occurred significantly more often in the group with HT during rest or following exposure to hot air or passive smoke. Awareness of phlegm or wheeze was reported with increased prevalence among subjects with tetraplegia who had complete injuries. Among subjects with tetraplegia, respiratory complaints did not differ significantly in current smokers, former smokers, and non-smokers, whereas among subjects with paraplegia, phlegm and wheeze were reported more frequently among current smokers.

Keywords: Spinal cord injury; paraplegia; tetraplegia; respiratory symptoms; breathlessness; cough

\section{Introduction}

Pulmonary function in subjects with chronic spinal cord injury (SCI) is influenced by a number of factors. Of primary importance, injury to the spinal cord can cause paralysis of inspiratory and expiratory respiratory muscles, resulting in restrictive ventilatory impairment, the severity of which is inversely associated with the level of injury. Ineffective cough and inability to breath deeply may lead to atelectasis and pneumonia, two of the most common causes of morbidity and mortality in these subjects. ${ }^{1,2}$ Additional factors that contribute to respiratory dysfunction include reduced lung compliance, possibly due to premature airway closure at the lung bases with associated microatelectasis, ${ }^{3-6}$ reduced chest wall compliance, ${ }^{3}$ and paradoxical inward movement of the chest wall during inspiration, ${ }^{4,7,8}$ leading to reduced efficiency of breathing. ${ }^{9}$ In addition, the majority of subjects with chronic cervical SCI have recently been demonstrated to have airway hyperreactivity following inhalation of methacholine or histamine, suggesting that exogenous agents may act as airway irritants to adversely affect overall respiratory status. ${ }^{10,11}$

Correspondence: Dr. AM Spungen, Spinal Cord Damage Research Center, Veterans Affairs Medical Center, 130 West Kingsbridge Road, Bronx, NY 10468 USA
The impact of respiratory dysfunction on subjective complaints in subjects with SCI has not been evaluated in detail. In a study of 34 subjects with complete tetraplegia or paraplegia that primarily addressed acceptability and reproducibility of spirometry, respiratory complaints included chronic cough, chronic phlegm, persistent wheeze, and any wheeze. ${ }^{12}$ However, only a limited number of respiratory symptoms were addressed in the study and respiratory complaints were not subcategorized based upon level of injury. In the current study by administration of a detailed respiratory questionnaire, ${ }^{13}$ the prevalence of respiratory symptoms in subjects with chronic SCI was determined and symptoms correlated with level of injury, completeness of injury and smoking status.

\section{Methods}

Characteristics of the study population

One hundred and eighty male subjects with chronic SCI ( $>1$ year) who were followed as outpatients by the Spinal Cord Injury Service, Veterans Affairs Medical Center, Bronx, NY, agreed to participate in a pulmonary symptom survey as part of their routine annual physical examination. Data on file included age, 
medications, family history, occupational history, and associated medical disorders. Subjects were categorized as high tetraplegia (HT; C5 and above not requiring mechanical ventilation), low tetraplegia (LT; C6-8), high paraplegia (HP; T1-7), or low paraplegia (LP; T8-L3). Based upon neurologic evaluations documented in the medical records, subjects were also categorized as having complete injuries (complete motor and sensory loss) or incomplete injuries (incomplete motor and/or sensory loss). Non-smokers were defined as those who had not used cigarettes $(<400$ in lifetime), cigars $(<1 /$ week for 1 year) and/or a pipe $\left(<12 \mathrm{oz}\right.$ of tobacco), ${ }^{13}$ former smokers as those who had quit smoking for at least 1 year, and current smokers as those who regularly used cigarettes, cigars and or a pipe or had ceased use for less than one year prior to the survey.

\section{Respiratory questionnaire}

The prevalence of respiratory symptoms was assessed using a standard respiratory questionnaire. ${ }^{13}$ The following instructions were given to each subject prior to participating in the study. "You have been asked to answer the following questions pertaining to your history of respiratory symptoms. Response to the questions are either yes or no. Answers of 'Yes' to these questions are to be apart from a cold. If you are in doubt about your response, then answer with a "no'." The only modification of the questionnaire was for subjects requiring assistance with dressing, who were asked 'Do you ever have breathlessness when you are being dressed or undressed?' instead of 'Do you ever have breathlessness when you are dressing or undressing?' The pulmonary questionnaire contained five major questions, each with their own subset of questions: (1) Do you ever have breathlessness? 'yes' responders were then asked an additional eleven questions relating to activity and exposure to exogenous airborne irritants; (2) Do you usually have a cough? (Include coughs with the first smoke or on first going outside. Exclude clearing of throat.) 'yes' responders were then asked an additional six questions related to frequency and time of day; (3) Do you bring up phlegm from your chest? (Include phlegm with first smoke or on first going outside. Include swallowed phlegm. Exclude phlegm from the nose.) 'yes' responders were then asked an additional three questions dealing with time-of-day and frequency; (4) Do you have cough and phlegm together? 'yes' responders were then asked two additional questions relating to frequency and duration; (5) Does your chest have wheezing or whistling sounds? 'yes' responders were then asked an additional five questions dealing with relationship to colds, time of day and dyspnea.

Data for each subject were stored in a computer data-base in a series of related tables, which were queried in various combinations to define data subsets for statistical analyses.
Statistical analysis

Statistical analyses were performed using Statview 4.5 software (Abacus Concepts, Inc., Berkeley, CA). All continuous variables were reported as mean plus or minus the standard error of the mean (mean \pm SEM). Descriptive statistics, frequency distributions or comparative statistics were reported on the variables by the categories for: level of lesion (LOL) (HT, LT, HP, and LP); completeness of lesion (COL) (complete and incomplete); and smoking history (current, former and never). Analysis of variance (ANOVA) was used for the continuous variables to compare among the four LOL, between the two COL and among the three smoking history categories for significant differences. A Sheffe' post hoc analysis was applied to significant ANOVA $F$ ratios to determine single degree of freedom significance among the pair-wise comparisons. Chi square analyses were used for comparison of the prevalence of respiratory symptoms by LOL, COL and smoking history categories. If the Chi square analysis was significant for any of the variables, then single degree of freedom tests were performed and a continuity corrected Chi square analysis was applied to the $2 \times 2$ tables with cells containing less than 20 subjects. Additionally, a comparison of population proportions was used to test for significant differences between the subjects in this study and those in the general population. ${ }^{14}$

\section{Results}

Characteristics of the subjects are shown in Table 1. Subjects with HT and LT were younger than those with HP; those with HT had a shorter duration of injury (DOI) than subjects with HP. Within the HT and LT groups significantly more subjects had incomplete lesions. The distribution of current, former and non-smokers did not differ significantly among the four groups. Sixty subjects were current smokers, of which 55 smoked cigarettes only, four smoked

Table 1 Characteristics of the subjects

\begin{tabular}{lcccc}
\hline & $\begin{array}{c}H T \\
(\mathrm{n}=30)\end{array}$ & $\begin{array}{c}L T \\
(\mathrm{n}=57)\end{array}$ & $\begin{array}{c}H P \\
(\mathrm{n}=35)\end{array}$ & $\begin{array}{c}L P \\
(\mathrm{n}=58)\end{array}$ \\
\hline Age (y) & $45 \pm 3^{*}$ & $47 \pm 2^{\circ}$ & $56 \pm 2$ & $53 \pm 2$ \\
Height (in) & $71 \pm 4$ & $70 \pm 0.3$ & $70 \pm 1$ & $69 \pm 1$ \\
Weight (lb) & $169 \pm 6$ & $171 \pm 5$ & $180 \pm 6$ & $172 \pm 4$ \\
DOI (y) & $13 \pm 2^{*}$ & $17 \pm 2$ & $25 \pm 3$ & $22 \pm 2$ \\
\%Incomplete (n) & $70(21)^{\bullet}$ & $81(46)^{\bullet}$ & $37(13)$ & $55(32)$ \\
\%Complete (n) & $30(9)$ & $19(11)$ & $63(22)$ & $45(26)$ \\
\%Current (n) & $23(7)$ & $40(23)$ & $23(8)$ & $38(22)$ \\
\%Former (n) & $27(8)$ & $35(20)$ & $46(16)$ & $41(24)$ \\
\%Never (n) & $50(15)$ & $25(14)$ & $31(11)$ & $21(12)$ \\
\hline
\end{tabular}

Definition of abbreviations: HT $=$ high tetraplegia; $\mathrm{LT}=$ low tetraplegia; $\mathrm{HP}=$ high paraplegia; $\mathrm{LP}=$ low paraplegia; DOI $=$ duration of injury; ${ }^{*} P<0.05$ for HT $v s$. HP; ${ }^{\circ} P<0.05$ for LT vs. HP; ${ }^{\circ} P<0.05$ for Incomplete $v s$. Complete within the respective group 
cigarettes and a pipe and/or a cigar ( $\geqslant 1 /$ day), and one smoked cigars only ( $\geqslant 1 /$ day).

The most common respiratory complaint was breathlessness, which was significantly more prevalent among subjects with HT and LT as compared with subjects with HP or LP (Table 2 and Figure 1A). Although subjects with HT reported more cough, cough combined with phlegm, and wheeze, the prevalence of cough, phlegm, cough and phlegm, wheeze, or any symptom did not differ significantly among the four groups (Table 2 and Figure 1A). Breathlessness was more prevalent among subjects with complete and incomplete tetraplegia as compared with subjects with complete and incomplete paraplegia (Table 3 and Figure 1b). Phlegm was more prevalent in subjects with complete tetraplegia versus those with incomplete lesions (Table 3 and Figure 1B). Wheeze was more prevalent in subjects with complete tetraplegia as compared with subjects with complete and incomplete paraplegia (Table 3 and Figure 1B). Symptoms occurred with equal frequency among subjects with paraplegia having complete or incomplete injuries (Figure 1B).

Breathlessness at rest was significantly more prevalent in subjects with HT, whereas breathlessness associated with activity or dressing was reported with nearly equal frequency among subjects with HT, LT, and HP, and not significantly less often by subjects with LP (Figure 2A). Subjects with HT reported increased breathlessness following exposure to a number of exogenous agents, with significant increase following exposure to hot air or secondary (passive) smoke (Figure 2B).

Among positive responders to cough, subjects with HT reported a higher (albeit nonsignificant) prevalence of cough occurring greater than four times per day, greater than 4 days per week, during the day, at night, and for greater than 3 months per year, compared with the other three LOL groups (Figure 3A). Among positive responders, phlegm occurred with nearly equal frequency in the four groups (Figure 3B). In response to the question, 'Does your cough and phlegm have increasing episodes?', significantly more subjects with HT responded

Table 2 Respiratory symptoms by level of lesion

\begin{tabular}{lllll}
\hline & $\begin{array}{c}H T \\
(\mathrm{n}=30)\end{array}$ & $\begin{array}{c}L T \\
(\mathrm{n}=57)\end{array}$ & $\begin{array}{c}H P \\
(\mathrm{n}=35)\end{array}$ & $\begin{array}{c}L P \\
(\mathrm{n}=58)\end{array}$ \\
\hline & $\%(n)$ & $\%(n)$ & $\%(n)$ & $\%(n)$ \\
Breathlessness & $73(22)^{*}$ & $58(33)^{\circ}$ & $43(15)$ & $29(17)$ \\
Cough & $23(7)$ & $14(8)$ & $20(7)$ & $19(11)$ \\
Phlegm & $33(10)$ & $28(16)$ & $34(12)$ & $29(17)$ \\
Cough \& Phlegm & $30(9)$ & $21(12)$ & $17(6)$ & $16(9)$ \\
Wheeze & $37(11)$ & $26(15)$ & $20(7)$ & $17(10)$ \\
Any Symptom & $80(24)$ & $74(42)$ & $66(23)$ & $59(33)$ \\
\hline
\end{tabular}

$\mathrm{HT}=$ high tetraplegia; $\mathrm{LT}=$ low tetraplegia; $\mathrm{HP}=$ high paraplegia; $\mathrm{LP}=$ low paraplegia. ${ }^{*} P<0.05$ for $\mathrm{HT}$ vs $\mathrm{HP}$ and $\mathrm{LP}$; ${ }^{\circ} P<0.05$ for LT $v s$ LP affirmatively as compared with subjects with HP (Figure 4a). The group also reported increased prevalence of cough and phlegm occurring greater

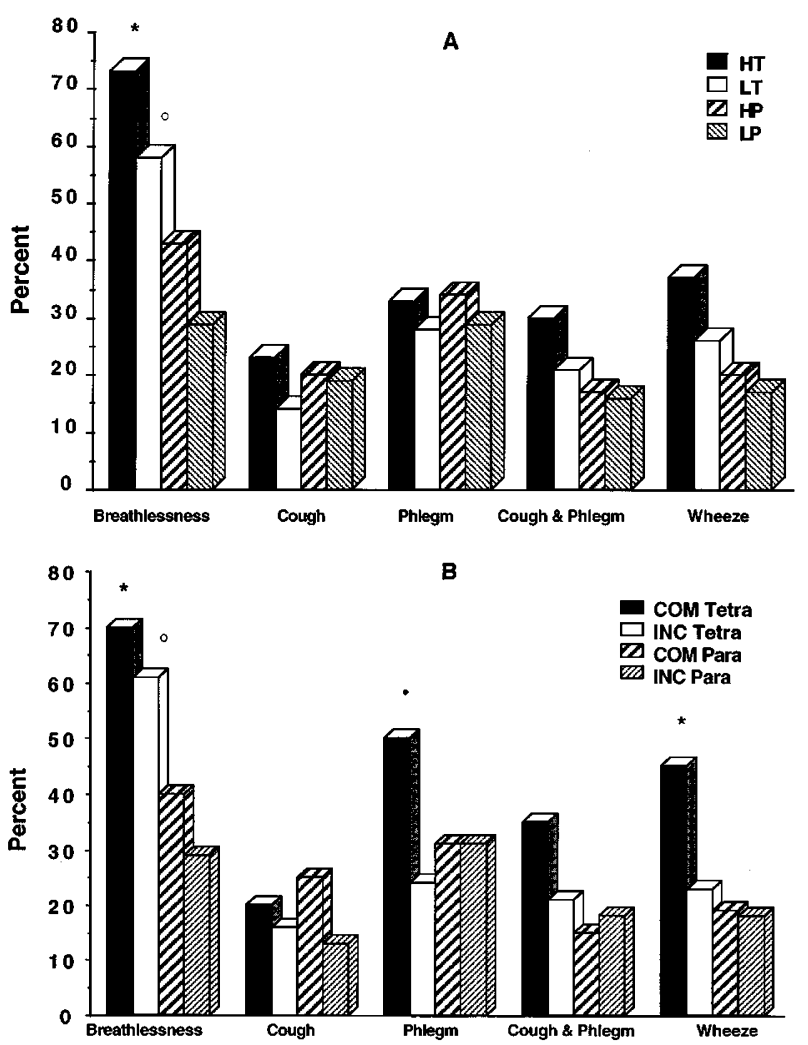

Figure 1 (A) Prevalence of respiratory symptoms among subjects with high tetraplegia (HT), low tetraplegia (LT), high paraplegia (HP), or low paraplegia (LP). ${ }^{*} P<0.05$ for HT versus $\mathrm{HP}$ and $\mathrm{LP} ;{ }^{\circ} \mathrm{P}<0.05$ for $\mathrm{LT}$ versus $\mathrm{LP}$. (B) Prevalence of respiratory symptoms among subjects with COM Tetra (complete tetraplegia), INC Tetra (incomplete tetraplegia), COM Para (complete paraplegia), INC Para (incomplete paraplegia). ${ }^{*} P<0.05$ for COM Tetra versus COM Para and INC Para; ${ }^{\circ} P<0.05$ for INC Tetra versus COM Para and INC Para; ${ }^{\bullet} P<0.05$ for COM Tetra versus INC Tetra

Table 3 Respiratory symptoms by completeness of lesion

\begin{tabular}{lllll}
\hline & $\begin{array}{l}\text { Com } \\
\text { Tetra } \\
(\mathrm{n}=20)\end{array}$ & $\begin{array}{l}\text { Inc } \\
\text { Tetra } \\
(\mathrm{n}=67)\end{array}$ & $\begin{array}{l}\text { Comm } \\
\text { Para } \\
(n=48)\end{array}$ & $\begin{array}{l}\text { Inc } \\
\text { Para } \\
(\mathrm{n}=45)\end{array}$ \\
\hline & $\%(n)$ & $\%(n)$ & $\%(n)$ & $\%(n)$ \\
Breathlessness & $70(14)^{*}$ & $61(41)^{\circ}$ & $40(19)$ & $29(13)$ \\
Cough & $20(4)$ & $16(11)$ & $25(12)$ & $13(6)$ \\
Phlegm & $50(10)^{\circ}$ & $24(16)$ & $31(15)$ & $31(14)$ \\
Cough \& Phlegm & $35(7)$ & $21(14)$ & $15(7)$ & $18(8)$ \\
Wheeze & $45(9)^{*}$ & $25(17)$ & $19(9)$ & $18(8)$ \\
Any Symptom & $85(17)$ & $73(49)$ & $65(31)$ & $56(25)$ \\
\hline
\end{tabular}

Com Tetra $=$ complete tetraplegia; Inc Tetra=incomplete tetraplegia; Com para $=$ complete paraplegia; Inc para $=$ incomplete paraplegia. $* P<0.05$ for Com Tetra $v s$ Com and Inc Para; ${ }^{\circ} P<0.05$ for Inc Tetra $v s$ Com and Inc Para; $\bullet P<0.05$ for Com Tetra vs Inc Tetra 

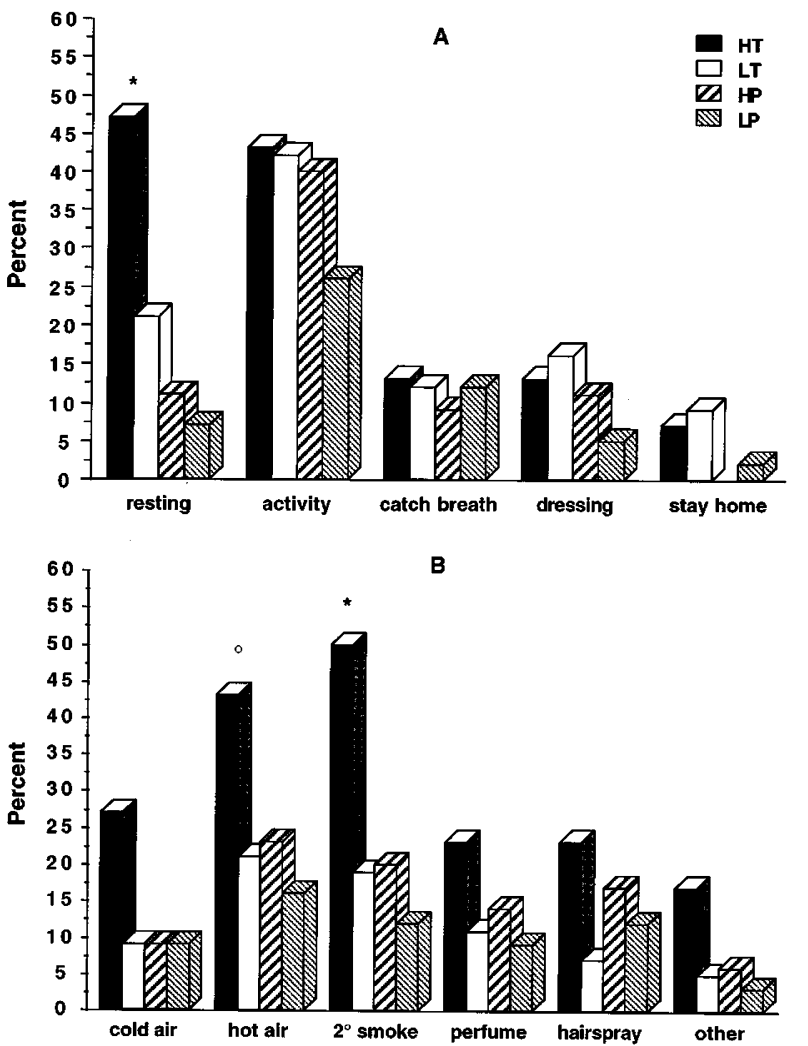

Figure 2 (A) Prevalence of breathlessness among positive responders at rest or during activity causing subjects to stop to catch their breath or stay home. $* P<0.05$ for HT versus LT, HP and LP. The HP group had $0 \%$ breathlessness causing them to stay at home. (B) Prevalence of breathlessness among positive responders following exposure to cold air, hot air, secondary (passive) smoke, perfume, hair spray, or other airborne irritants. ${ }^{*} P<0.05$ for HT versus LT and LP; ${ }^{\circ} P<0.05$ for HT versus LT, HP, and LP

than 3 weeks per year, although the increase did not reach statistical significance. Among responders to wheeze, subjects with HT reported a higher prevalance of wheeze without colds, during the day, and at night, although the differences did not reach statistical significance (Figure 4B). However, wheeze combined with breathlessness (dyspnea) was significantly more prevalent in subjects with HT and LT as compared with subjects with LP (Figure 4B).

Among subjects with tetraplegia, respiratory symptoms were unrelated to smoking status, whereas among subjects with paraplegia, phlegm and wheeze were significantly more prevalent among current smokers (Figure $5 \mathrm{~A}$ and $\mathrm{B}$ ).

\section{Discussion}

We found that 122 of the 180 study subjects $(68 \%)$ reported one or more respiratory symptom, with breathlessness, the most frequent complaint, being reported by $48 \%$ of the subjects. The higher
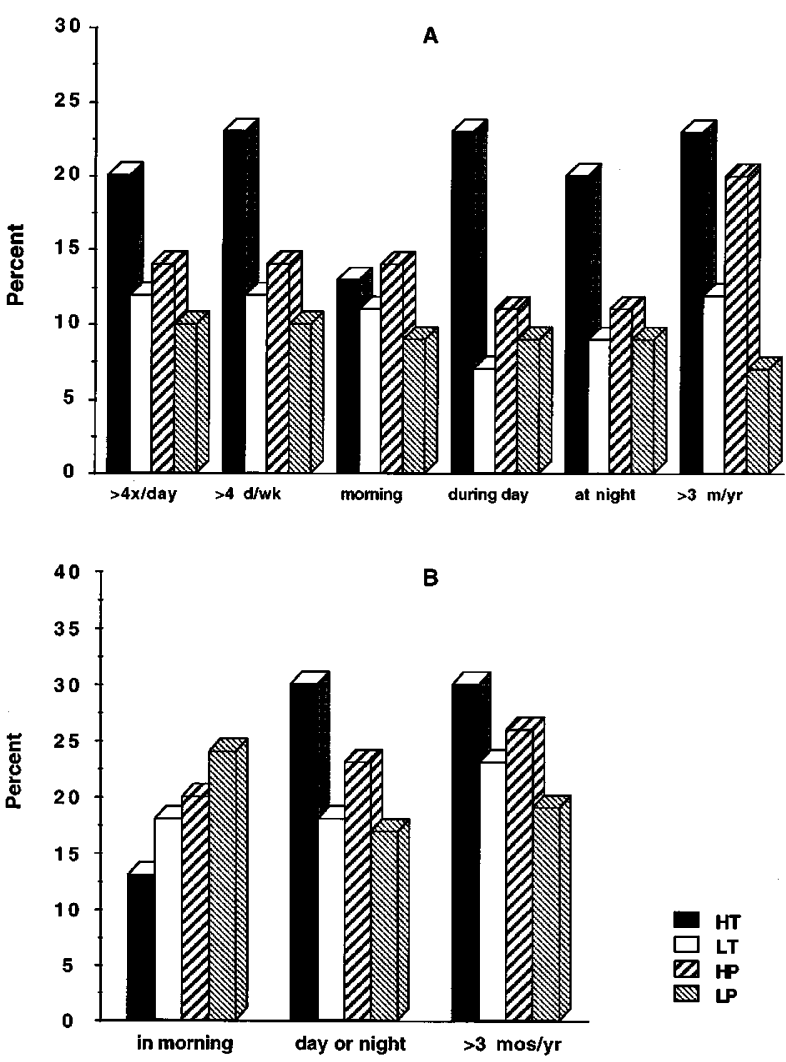

Figure 3 (a) Prevalence of cough among positive responders for more than four times a day, more than 4 days a week, in the morning, throughout the day, at night, or for greater than 3 months per year. (b) Prevalence of phlegm in the morning, day or night, and for more than 3 months per year

prevalence of breathlessness among subjects with HT $(73 \%)$ and LT $(58 \%)$ is attributed largely to loss of inspiratory muscle function. Breathlessness among subjects with HP and LP presumably reflects loss of intercostal and abdominal muscle function. Findings of breathlessness among subjects with $\mathrm{HT}>\mathrm{LT}>\mathrm{HP}>\mathrm{LP}$ is consistent with observations that the severity of overall respiratory impairment following spinal cord injury is inversely associated with the level of lesion. ${ }^{15}$ Additional causes for breathlessness in subjects with tetraplegia may include increased work of breathing, ${ }^{16,1}$ partial loss of diaphragm and accessory muscle function, ${ }^{18}$ paradoxical movement of the chest wall with inspiration, ${ }^{8,9}$ reduced lung and chest wall compliance, ${ }^{3,4}$ and airway hyperreactivity. ${ }^{10,11}$ As a result, among subjects with tetraplegia breaths are more shallow and rapid with a shorter expiratory time, which may predispose to ventilatory muscle fatigue. ${ }^{19}$

The prevalence of respiratory symptoms was not associated with smoking status among subjects with tetraplegia, suggesting that pulmonary complaints associated with compromised respiratory function caused by paralysis of the major and minor 


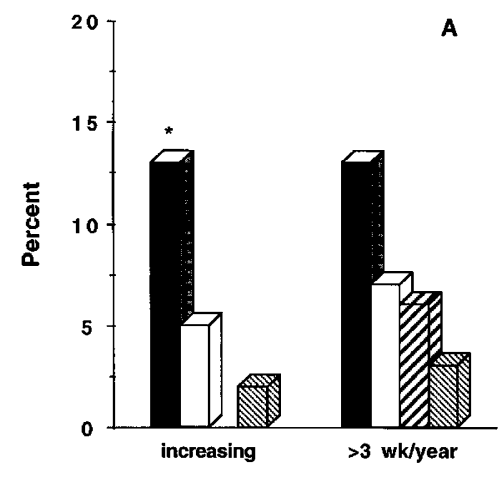

B

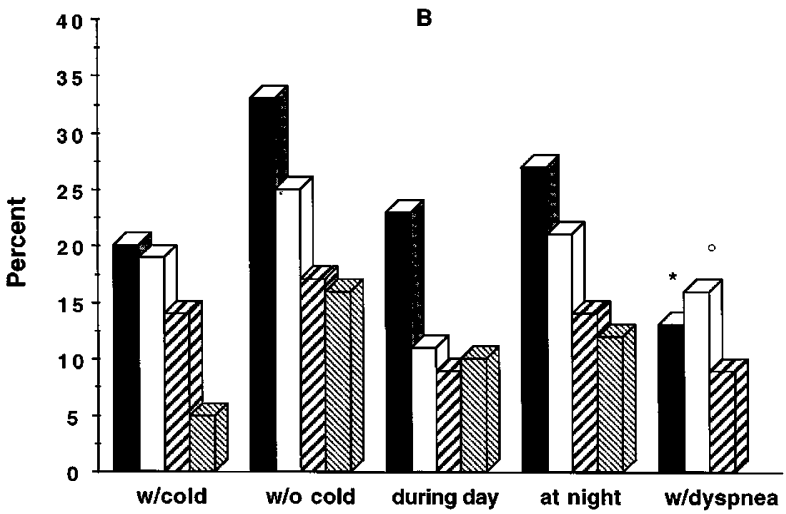

Figure 4 (A) Prevalence of cough combined with phlegm among positive responders for increasing episodes or occurring greater than three weeks per year. $* P<0.05$ for HT versus HP. The HP group had $0 \%$ cough and phlegm with increasing episodes. (B) Prevalence of wheeze among positive responders with colds, without colds, during the day, at night, or in association with dyspnea (breathlessness). ${ }^{*} P<0.05$ for HT versus $\mathrm{LP} ;{ }^{\circ} P<0.05$ for $\mathrm{LT}$ versus LP. The LP group had $0 \%$ wheeze associated with breathlessness

respiratory muscles overshadows those caused by chronic cigarette use. In contrast, complaints of phlegm and wheeze were significantly more prevalent among subjects with paraplegia who were current smokers, indicating that even though variable degrees of intercostal and abdominal muscle loss occurs with thoracic lesions, associated respiratory symptoms do not mask those caused by smoking.

Although a standard epidemiology respiratory questionnaire was used in the current study, with modification only of a single question dealing with dressing, the questionnaire was not administered to a male veteran control group, a limitation of the study. However, by use of the standard questionnaire, Sherman et al. quantitated respiratory symptoms in 1757 healthy able-bodied men with a mean age of 47.5 years, comparable to that of our SCI population. ${ }^{20}$ The normal male subjects were selected from census lists from six cities in the eastern United States. Thirty-five percent were current smokers, 35\% former smokers and $30 \%$ non-smokers, similar to those of our
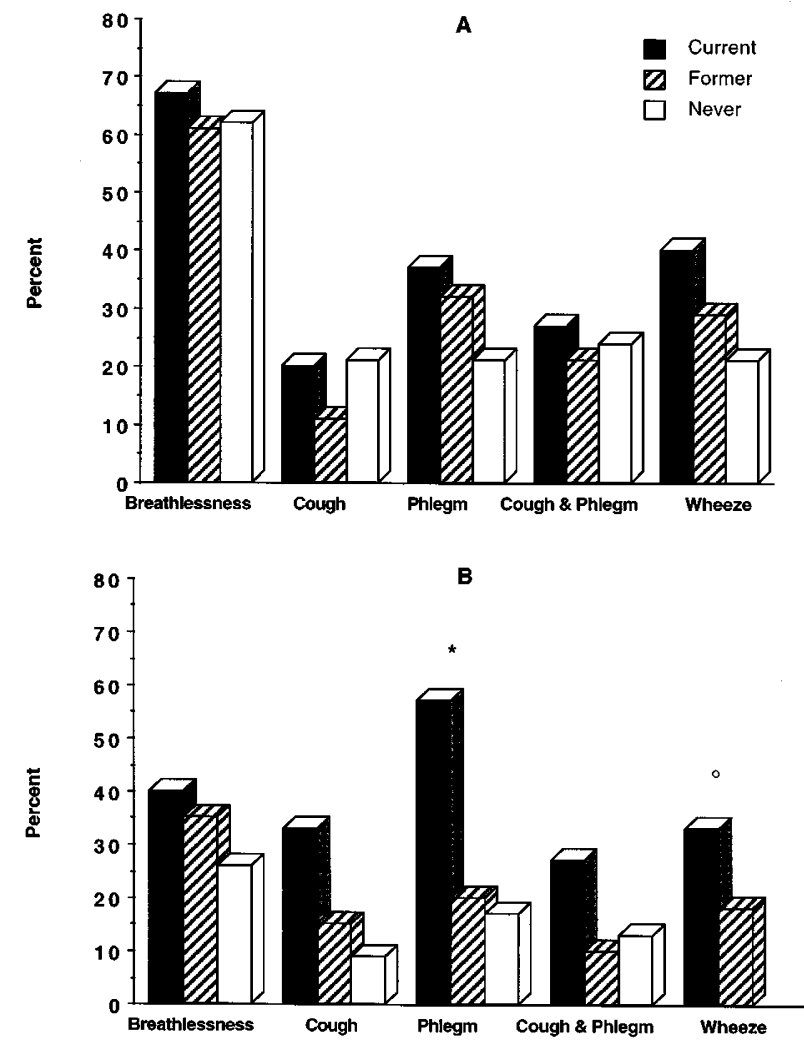

Figure 5 Prevalence of respiratory symptoms among subjects with tetraplegia (A) or paraplegia (B) who were current, former, or non-smokers. ${ }^{*} P<0.05$ for current versus former or non-smoker; ${ }^{\circ} P<0.05$ for current versus non-smoker. The LP non-smoker group had $0 \%$ wheeze

study group $(33 \%, 38 \%$ and $29 \%$, respectively). By comparison of current findings with those obtained by Sherman et $a .^{20}$ it is apparent that complaints of breathlessness, or any symptom, in subjects with tetraplegia or paraplegia in all smoking categories far exceeded those observed in the general population (Table 4). In addition, among subjects with tetraplegia, wheeze was more prevalent among current and former smokers and all symptoms were more prevalent among non-smokers. Among subjects with paraplegia, phlegm and wheeze were more prevalent among current smokers and wheeze was more prevalent among former smokers. ${ }^{20}$

It is unknown whether respiratory symptoms among subjects with SCI correlate with long-term pulmonary function decline or increased mortality. Among ablebodied men, the reporting of any respiratory symptom was associated with a reduction in initial lung function and more rapid decline in height-adjusted forced expiratory volume in one second (FEV1). ${ }^{20}$ In addition, after adjustment for height, age and cigarette smoking, healthy men with cough or phlegm demonstrated accelerated loss in FEV1. In a study of the natural history of chronic airflow obstruction, symptoms of cough and phlegm, wheeze, and breath- 
Table 4 Respiratory symptoms and smoking

\begin{tabular}{|c|c|c|c|}
\hline & \multicolumn{3}{|c|}{ Current Smokers } \\
\hline & $\begin{array}{l}\text { Tetraplegia } \\
\quad(n=30)\end{array}$ & $\begin{array}{l}\text { Paraplegia } \\
\quad(n=30)\end{array}$ & $\begin{array}{l}\text { Sherman et al } \\
\quad(n=608)\end{array}$ \\
\hline & $\% \quad(n)$ & $\%(n)$ & $\%(n)$ \\
\hline Breathlessness & $67(20)^{*}$ & $40(12)^{*}$ & $4 \quad(26)$ \\
\hline Cough & $20(6)$ & $33(10)$ & $28(169)$ \\
\hline Phlegm & $37(11)$ & $57(17)^{*}$ & $27(166)$ \\
\hline Wheeze & $40(12)^{*}$ & $33(10)^{*}$ & $14 \quad(84)$ \\
\hline \multirow[t]{4}{*}{ Any Symptom } & $83(25)^{*}$ & $77(23)^{*}$ & $43(260)$ \\
\hline & \multicolumn{3}{|c|}{ Former Smokers } \\
\hline & $\begin{array}{l}\text { Tetraplegia } \\
\quad(n=28)\end{array}$ & $\begin{array}{l}\text { Paraplegia } \\
(n=40)\end{array}$ & $\begin{array}{l}\text { Sherman et al } \\
\quad(n=622)\end{array}$ \\
\hline & $\%(n)$ & $\%(n)$ & $\%(n)$ \\
\hline Breathlessness & $61(17)^{*}$ & $35(14)^{*}$ & $3 \quad(21)$ \\
\hline Cough & 11 (3) & 15 (6) & $7 \quad(46)$ \\
\hline Phlegm & 32 (9) & $20 \quad(8)$ & $11 \quad(71)$ \\
\hline Wheeze & $29(8)^{*}$ & $18(7)^{*}$ & $5 \quad(28)$ \\
\hline \multirow[t]{4}{*}{ Any Symptom } & $75(21)^{*}$ & $55(22)^{*}$ & $18(112)$ \\
\hline & \multicolumn{3}{|c|}{ Never Smokers } \\
\hline & $\begin{array}{l}\text { Tetraplegia } \\
\quad(n=29)\end{array}$ & $\begin{array}{l}\text { Paraplegia } \\
\quad(n=23)\end{array}$ & $\begin{array}{l}\text { Sherman et al } \\
\quad(n=527)\end{array}$ \\
\hline & $\% \quad(n)$ & $\%(n)$ & $\%(n)$ \\
\hline Breathlessness & $62(18)^{*}$ & $26(6)^{*}$ & $2(22)$ \\
\hline Cough & $21(6)^{*}$ & 9 (2) & $5(25)$ \\
\hline Phlegm & $21(6)^{*}$ & 17 (4) & $6(29)$ \\
\hline Wheeze & $21 \quad(6)^{*}$ & $\begin{array}{ll}0 & (0)\end{array}$ & $2(12)$ \\
\hline Any Symptom & $69(20)^{*}$ & $48(11)^{*}$ & $10(52)$ \\
\hline
\end{tabular}

$* P<0.05$ for Tetraplegia or Paraplegia vs Sherman et al. (20)

lessness were significantly associated with all-cause mortality. ${ }^{21}$ For both smokers and non-smokers, the presence of chronic cough and/or sputum production was related to mortality only in the presence of wheezing. Among smokers, the presence of both cough and phlegm and wheeze was significantly associated with mortality only among subjects with low initial lung function. ${ }^{21}$

Clearly, however, therapeutic interventions are warranted to discourage smoking in subjects with SCI because of underlying injury-related compromised lung function, even though smoking-related effects on pulmonary symptoms were not apparent in the tetraplegia group. Because of possible aggravation of breathlessness, subjects with HT should be instructed to avoid inhalation, if possible, of hot air and passive smoke. Also, previous findings that approximately $45 \%$ of subjects with tetraplegia demonstrate bronchodilation following inhalation of metaproterenol sulfate ${ }^{22}$ or ipratropium bromide, ${ }^{23}$ suggest that provision of bronchodilatory therapy may provide symptomatic benefit in this population.

\section{References}

1 DeVivo MJ, Kartus PL, Stover SL, Rutt RD, Fine PR. Cause of death for patients with spinal cord injuries. Arch Intern Med 1989; 149: $1761-1766$

2 Mansel JK, Norman JR. Respiratory complications and management of spinal cord injuries. Chest 1990; 97: 1446-1452.

3 De Troyer A, Heilporn A. Respiratory mechanics in tetraplegia. The respiratory function of the intercostal muscles. Amer Rev Respir Dis 1980; 122: $591-600$.

4 Scanlon PD, Loring SH, Pichurko BM, McCool FD, Slutsky AS, Sarkarati M, Brown R. Respiratory mechanics in acute tetraplegia: lung and chest wall compliance and dimensional changes during respiratory maneuvers. Am Rev Respir Dis 1989; 139: $615-620$.

5 Bake B, Fugl-Meyer AR, Grimby G. Breathing patterns and regional ventilation distribution in tetraplegic patients and in normal subjects. Clin Sci 1972; 42: 117-128.

6 Stone DJ, Keltz H. The effect of respiratory muscle dysfunction on pulmonary function: Studies in patients with spinal cord injuries. Am Rev Respir Dis 1963; 88: 621-629.

7 Estenne M, De Troyer A. Relationship between respiratory muscle electromyogram and rib cage motion in tetraplegia. $\mathrm{Am}$ Rev Respir Dis 1985; 132: $53-59$.

8 De Troyer A, Estenne M, Vincken W. Rib cage motion and muscle use in high tetraplegics. Am Rev Respir Dis 1986; 133: $1115-1119$.

9 Manning H, McCool FD, Scharf SM, Garshick E, Brown R. Oxygen cost of resistive-loaded breathing in tetraplegia. $J$ Appl Physiol 1992; 73: 825-831.

10 Dicpinigaitis PV, Spungen AM, Bauman WA, Absgarten A, Almenoff PL. Bronchial hyperresponsiveness after cervical spinal cord injury. Chest 1994; 105: 1073 - 1076.

11 Fein ED, Grimm DR, Lesser M, Bauman WA, Almenoff PL. The effects of ipratropium bromide on histamine-induced broncho constriction in subjects with cervical spinal cord injury. Journal of Asthma, in press.

12 Ashba J, Garshick E, Tun CG, Lieberman SL, Polakoff DF, Blanchard JD, Brown R. Spirometry: Acceptability and reproducibility in spinal cord injured subjects. J Am Paraplegia Soc 1993; 16: $197-203$

13 Ferris BG Jr. Epidemiology standardization project. Am Rev Respir Dis 1978; 118: 55-88.

14 McGee JW. Introductory Statistics. West Pub. Comp. St. Paul, MN. 10: $351-394$.

15 Almenoff PL, Spungen AM, Lesser M, Bauman WA. Pulmonary function survey in spinal cord injury: Influences of smoking and level and completeness of injury. Lung 1995; 173: 297-306.

16 Bergofsky EH. Mechanism for respiratory insufficiency after cervical cord injury: A source of alveolar hypoventilation. Ann Intern Med 1964; 61: $435-447$.

17 Lanig IS, Lammertse DP. The respiratory system in spinal cord injury. Phys Med Rehab Clin NA 1992; 3: 725-739.

18 Bergofsky EH. Quantitation of the function of respiratory muscles in normal individuals and quadriplegic patients. Arch Phys Med Rehabil 1964; 45: 575-580.

19 Loveridge BM, Dubo HI. Breathing pattern in chronic tetraplegia. Arch Phys Med Rehabil 1990; 71: 495-499.

20 Sherman CB, Xu X, Speizer FE, Ferris BG Jr, Weiss ST, Dockery DW. Longitudinal lung function decline in subjects with respiratory symptoms. Am Rev Respir Dis 1992; 146: 855-859.

21 Vollmer WM, McCamant LE, Johnson LR, Buist AS. Respiratory symptoms, lung function, and mortality in a screening center cohort. Am J Epidemiol 1989; 129: 1157-1169.

22 Spungen AM, Dicpinigaitis PV, Almenoff PL, Bauman WA. Pulmonary obstruction in individuals with cervical spinal cord lesions unmasked by bronchodilator administration. Paraplegia 1993; 31: 404-407.

23 Almenoff PL, Alexander LR, Spungen AM, Lesser M, Bauman WA. Bronchodilatory effects of ipratropium bromide in patients with tetraplegia. Paraplegia 1995; 33: 274-277. 